\title{
Stress factors vs. job satisfaction among nursing staff in the Pomeranian Province (Poland) and the Vilnius Region (Lithuania)
}

\author{
Katarzyna Kwiecień-Jaguś',B-F, Wioletta Mędrzycka-Dąbrowska',A-F, Andrzej Chamienia ${ }^{1, A, E-F}$, \\ Viktorija Kielaite ${ }^{2, B-D}$ \\ ${ }^{1}$ Medical University, Gdańsk, Poland \\ ${ }^{2}$ Vilniaus Kolegija/ University of Applied Sciences and Vilniaus University, Vilnius, Lithuania \\ A - Research concept and design, B - Collection and/or assembly of data, C - Data analysis and interpretation, \\ $D$ - Writing the article, E-Critical revision of the article, F- Final approval of article
}

Kwiecień-Jaguś K, Mędrzycka-Dąbrowska W, Chamienia A, Kielaite V. Stress factors vs. job satisfaction among nursing staff in the Pomeranian Province (Poland) and the Vilnius Region (Lithuania). Ann Agric Env Med. 2018; 25(4): 616-624. doi: 10.26444/aaem/75801

\begin{abstract}
Introduction. In the opinion of many researchers, nursing staff are exposed to an exceptionally high level of occupational stress. The problem of stress in the working environment of the nursing staff becomes more and more important in the context of increasing staff shortages and insufficient support from colleagues and employers. The aim of this study was to analyse stress factors indicated by the nursing staff in Poland and Lithuania, and to assess their job satisfaction.

Materials and method. Two standard research tools were used in the study: the Nursing Stress Scale and the Job Satisfaction Survey. The study involved 230 respondents from Poland and Lithuania. The sample was chosen randomly and incidentally. Results. Based on the analysis of collected materials, the greatest stress factors in the work of the nursing staff were identified, which included interpersonal conflicts between nurses and doctors and between nurses, and death and dying. The study indicated that there is a relationship between stress and job satisfaction among Polish nurses $(r=-0.33 ; p=0.001)$ and Lithuanian nurses $(r=0.34 ; p=0.001)$. The greater the stress, the lower the job satisfaction. Low job satisfaction was connected with low remuneration, which is still inadequate to professional duties, and the lack of promotion opportunities. The study confirmed that there were significant differences in job satisfaction among Polish and Lithuanian nurses ( $Z=-6.27$; $\mathrm{p}<0.001)$.
\end{abstract}

Conclusions. The study confirmed a high level of stress and dissatisfaction among nursing staff in Poland and Lithuania.

Key words

Poland, Lithuania, job satisfaction, stress, nurses, nursing

\section{INTRODUCTION}

The multiple factors affecting human health include the conditions of professional work; if these are good, work becomes the source of professional satisfaction and positively affects the condition of the employees. Stress is inherent to the work of medical staff at healthcare establishments [1]. According to many researchers, the work of nursing staff is characterized by a particularly high level of occupational stress [2]. The first attempts at investigating the sources of stress in the workplace environment and the ways of coping with it were described in 1984 by Lazarus and Folkman, according to whom stress should be understood as a relationship between a person and his/her surroundings, evaluated by the person as a burden or as exceeding their resources and threatening their well-being [3]. Obviously, apart from the character of the job and workplace environment, the individual's psychological traits and capacity to deal with stressful situations are not insignificant [4]. The results of research into the sources of stress in nursing staff to-date point to the multidimensionality of the issue. The work of a nurse is complex and difficult, requiring great manual dexterity while performing procedures [5]. The problem of stress in

Address for correspondence: Katarzyna Kwiecień-Jaguś, Medical University Gdańsk, Poland

e-mail: kasiad124@gumed.edu.pl

Received: 15.05.2017; accepted: 11.07.2017; first published: 19.09.2017 the work environment of nursing staff gains importance in the light of increasing staff shortages [6], and insufficient support from colleagues and employers. Source literature shows that the levels of stress and job satisfaction in the work environment of nursing staff are of the utmost significance for the recruitment of new employees, and decisions to leave the workplace [7]. This is confirmed by Larrabee et al. [8], who showed that nursing staff who are satisfied with their workload, clinical challenges, and opportunities for professional development are 2.4 times less willing to change their workplace. The classical areas crucial for job satisfaction include economical aspects (pay, awards, welfare), conditions of work, organisation culture, and relationships with coworkers and superiors [9]. Job satisfaction is also determined by the employees' experience and their expectations towards work [10].

Available literature on the subject widely describes the problem of stress and the influence of stress on job satisfaction in highly developed countries. Although job satisfaction has been studied in the USA, UK, Scotland, Germany and Australia [7, 11], there are few research studies that analyse the problem of stress and job satisfaction among nursing staff in countries of the former Soviet block, including Poland and Lithuania. Both countries were under the strong influence of socialist ideologies for a very long time $[12,13]$.

The first attempts to classify sources of stress in the nursing staff group in Lithuania were initiated over 10 years ago in 
intensive care units [14]. Two years later, the first research into job satisfaction among nurses in Lithuania was published and covered the problem of occupational burnout in cardiology wards [15]. In Poland, too, the problem of stress and job satisfaction among the nursing staff is not new, but in the light of the lack of organisational solutions at workplaces and improvement in this area, they seem to have been forgotten [16]. The nursing profession in Poland is one of the top social trust professions [17]. Despite this high assessment, the work of the nursing staff is still undervalued. This is clearly indicated given the evaluation of working conditions and job satisfaction among nursing staff with long work experience [18]. Because of insufficient system solutions, as well as the lack of opportunities for further development $[16,18]$, the interest in nursing is not satisfactory [19].

Lithuania, similar to other European countries, including Poland, has faced the problem of shortages in the nursing staff for a long time. In accordance with statistical data from 2017, an estimated 538 nurses serve 100,000 inhabitants. In Poland, there are 134,539 registered and working nurses and midwives, but there is no detailed information about the number of nursing staff per 100,000 inhabitants [20]. For example, in other European countries, this ratio is much higher and reaches: Slovenia 86.1/10,000, Czech Republic 87.9/10,000, Norway 319/10,000, Finland 174/10,000, Switzerland 159/10,000, and Sweden 150/10,000 [21].

\section{OBJECTIVE}

The purpose of this study was to analyse the stress factors indicated by the nursing staff in Poland and Lithuania, and assess their job satisfaction.

\section{MATERIALS AND METHOD}

The study utilized a descriptive, comparative research design. For the purpose of the study, nurses employed in (public and private) health care centres in the Pomeranian Province in Poland and the Vilnius Region were invited to participate The study subjects were employees of different healthcare establishments such as hospitals (internal and cardiology departments, emergency departments, anesthesiology and intensive care units), primary health care, the teaching and educational community, and nursing homes. In the Pomeranian Province, the study involved 3 hospitals, whereas in the Vilnius Region the research project was conducted also in 3 public hospitals, as well as one private medical centre, 2 primary health care centres and 2 nursing homes. The sample was chosen randomly and incidentally. Each nurse who agreed to take participate in the project was informed that the study was anonymous and that the outcome would be used solely for scientific purposes. Questionnaires prepared for the study were distributed in health care centers by members of the research team. A representative of the research team provided each nurse taking part in the study with a questionnaire and a covering letter, instructions, and an unmarked white envelope. Having filled in the questionnaire, the respondents were requested to leave it in a specially prepared box. The plan was to distribute the questionnaires to 500 respondents. 230 nurses agreed to take part in the study, of whom 18 filled-in questionnaires incorrectly and were excluded from the statistical analysis. Representatives of other medical professions - doctors, paramedics, dieticians, physiotherapists and pharmacists, could not participate in the research project. The project was multicenter and took over a year to complete.

Self-report questionnaires were used for data collection. To analyze the specific stressors associated with the daily work of nursing staff, the project used a standardized study tool, namely, the Nursing Stress Scale NSS), designed by Gray-Toft and Anderson [22], and includes 34 statements on potentially stressful situations in the daily work of nursing staff. According to the original key, responses are given on the basis of a 4-point Likert-type scale, where 'never' is allocated one point, and 'very often' is allocated 4 points. The total points scored by marking the appropriate response indicate the degree of the respondent's attitude to the particular experience. The higher the score, the higher the stress rate. According to the original key, particular statements on the scale should be classified under one of 7 measures of stressful situations in a nurse's work, including the following issues: nurse-physician conflicts, nurse-nurse conflicts, inadequate preparation, lack of support from co-workers and employers, workload and uncertainty about diagnostic treatment, death and dying [22].

The second scale used to evaluate job satisfaction was the Job Satisfaction Survey (JSS) developed by Paul S. Spector [23] at the University of Florida in the USA, which contains 36 questions/statements concerning job satisfaction. The scale was created especially for the purposes of research for human service, public, and non-profit sector organizations, although it may also be applicable in other analyses. Answers are scored in line with the key on the basis of a 6-grade scale, where the answer 'disagree very much' scores one point, and the answer 'agree very much' scores 6 points. The total number of points obtained as a result of the selection of the answer by the respondent reflects the strength of his/her attitude towards a given feeling. The higher the number of points, the higher the job satisfaction index. The mean point value exceeding 4 is tantamount to job satisfaction, while answers with the mean value of 3 or less reflect dissatisfaction with work. Mean scores between 3-4 reflect ambivalence. For the 36-item total, where possible scores range from 36-216, the ranges are 36108 for dissatisfaction, $144-216$ for satisfaction, and between 108-144 for ambivalence Approximately half of the items were written in a positively-worded direction and about half in a negatively-worded direction. Each item was an evaluative statement, agreement with which would indicate either a positive or negative attitude towards the job. For negative questions, calculations were based on a reversed scoring system in compliance with the original answer key. The answer 'disagree very much' scores 6 points, while the answer 'agree very much' scored one point. The JSS scale measures 9 aspects of job satisfaction, including: satisfaction with pay, promotional opportunities, fringe benefits, contingent rewards (appreciation and recognition), supervision, coworkers, the nature of work itself, communication, and work conditions [24].

The authors gave their consents to use the questionnaires in the study. In order for the survey to be carried out among Lithuanian nurses, all the questionnaires were translated into Lithuanian, and then back-translated into English and verified against the original by a native speaker to check the accuracy of the translation. The original versions of the tools 
were analyzed in terms of factor accuracy, internal coherence and discriminating strength. Reasoning on the internal consistency of the questionnaire scales was performed by calculating Cronbach's a coefficient of internal consistency. The psychometric parameters obtained were satisfactory. The Cronbach's coefficient of reliability in Polish studies for the NNS scales and the JSS scale was 0.925 and 0.747 . For the study conducted in Lithuania, the reliability coefficient for the NNS was 0.847 , while for the JSS scale -0.799 .

Ethical considerations. The study was conducted in the Department of General Nursing at the Medical University in Gdańsk, Poland, in co-operation with the Vilniaus Kolegija and the University of Applied Sciences in Vilnius, Lithuania, and the Department of Research on the Quality of Life of the Medical University of Gdańsk. The project received the approval of the Independent Ethics Committee for Scientific Research at the Medical University of Gdańsk (No. NKBBN/239/2012).

Statistical analysis. All the statistical calculations were performed on IBM SPSS 20 software and an Excel spreadsheet. The structure of the study population was described using the sample size and percentage values (percent). Quantitative variables were characterized by means of arithmetic mean, standard deviation, median, and minimum and maximum value. Correlation analysis was used to determine the correlation between particular variables and their strength, by calculating Spearman's rank correlation coefficient. The significance of differences were assessed by means of the Mann-Whitney $U$ test, and the significance of differences between more than 2 groups was verified by means of the Kurskall-Wallis test if the ANOVA test applicability conditions were not met. For a model of 2 correlated variables, Wilcoxon signed-rank test was used (if the conditions for using Student's t-test were not fulfilled, or for variables measured on an ordinal scale). The significance level assumed in all the calculations was $\mathrm{p}<0.05$.

\section{RESULTS}

Socio-demographic characteristics. 230 respondents participated in the study, of whom 212 correctly completed the questionnaires and were included in the follow-up statistical analysis - 106 from Poland and 106 from Lithuania. Most of subjects, both in Poland and Lithuania, were women. The age of respondents ranged from 22-57, with largest group were respondents aged 31-40. In Poland, they accounted for $39.6 \%(n=42)$, and in Lithuania $-40.6 \%(n=43)$. The second, similarly numerous group were respondents aged 41-50. In Lithuania, they accounted for $41.5 \%(n=44)$, and in Poland for more than $36.8 \%(n=38)$. An analysis of the studied nurses' education showed that a bachelor's degree was predominant in both study groups. The work seniority of the studied nurses was examined in terms of overall seniority. The most numerous group of respondents were nursing staff with 16-20 years' experience. In Poland, their percentage was $29.2 \%(n=31)$, and in Lithuania $-21.7 \%(n=23)$. The second similarly numerous group were employees with $21-25$ years experience $-22.6 \%(n=24)$ in Lithuania, and $17.9 \%(n=19)$ in Poland. The vast majority of the nursing staff declared being employed at a single establishment; more than $6.6 \%$ $(n=7)$ of Lithuanian nurses were employed simultaneously at 3 establishments, and in Poland they accounted for $1.9 \%$ $(n=2)$. The detailed socio-demographic structure is shown in Table 1.

Table 1.

\begin{tabular}{|c|c|c|c|}
\hline \multirow[b]{2}{*}{ GENERAL CHARACTERISTICS: } & \multicolumn{2}{|c|}{ COUNTRY } & \multirow[b]{2}{*}{$p$-value } \\
\hline & $\begin{array}{l}\text { Lithuania } \\
\qquad \mathrm{N}(\%)\end{array}$ & $\begin{array}{l}\text { Poland } \\
\mathrm{N}(\%)\end{array}$ & \\
\hline \multicolumn{4}{|l|}{ GENDER } \\
\hline FEMALE & 105(99.1) & 105(99.1) & \\
\hline MALE & $1(0.9)$ & $1(0.9)$ & \\
\hline \multicolumn{4}{|l|}{ AGE } \\
\hline $22-30$ & $13(12.3)$ & $18(17.0)$ & \multirow{4}{*}{$\begin{array}{c}\mathrm{Chi}^{2}=16.49 \\
\mathrm{p}=0.057\end{array}$} \\
\hline $31-40$ & $43(40.6)$ & $42(39.6)$ & \\
\hline $41-50$ & $44(41,5)$ & $39(36.8)$ & \\
\hline $51-57$ & $6(5.7)$ & $7(6.6)$ & \\
\hline \multicolumn{4}{|l|}{ RESIDENCE } \\
\hline TOWN & 99(93.4) & $91(85.8)$ & \multirow{2}{*}{$\begin{array}{c}\mathrm{Chi}^{2}=0.01 \\
\mathrm{p}=0,992\end{array}$} \\
\hline COUNTRY & $7(6.6)$ & $15(14.2)$ & \\
\hline \multicolumn{4}{|l|}{ MARITAL STATUS } \\
\hline MARRIED & $91(85.8)$ & $70(66.0)$ & \multirow{2}{*}{$\begin{array}{c}C h i^{2}=3.31 \\
p=0.069\end{array}$} \\
\hline SINGLE & $15(14.2)$ & $36(34.0)$ & \\
\hline \multicolumn{4}{|l|}{ EDUCATION } \\
\hline $1^{\circ}$ IN NURSING & $82(77.4)$ & $63(59.4)$ & \multirow{4}{*}{$\begin{array}{c}\mathrm{Chi}^{2}=2.59 \\
\mathrm{p}=0.978\end{array}$} \\
\hline $2^{\circ}$ IN NURSING & $20(18.9)$ & $37(34.0)$ & \\
\hline $1^{\circ}$ IN OTHER FIELDS & $3(2.8)$ & $1(0.9)$ & \\
\hline $2^{\circ}$ IN OTHER FIELDS & $1(0.9)$ & $5(4.7)$ & \\
\hline \multicolumn{4}{|l|}{ POSITION } \\
\hline UNIT NURSE & $81(76.4)$ & 96(90.6) & \multirow{5}{*}{$\begin{array}{c}\mathrm{Chi}^{2}=7.30 \\
\mathrm{p}=0.121\end{array}$} \\
\hline NURSE COORDINATOR & $17(16.0)$ & $3(2.8)$ & \\
\hline WARD NURSE & $0(0)$ & $7(6.6)$ & \\
\hline HEAD NURSE & $6(5.7)$ & - & \\
\hline OTHER & $2(1.9)$ & - & \\
\hline \multicolumn{4}{|l|}{ SENIORITY } \\
\hline $1-5$ & $12(11.3)$ & $14(13.2)$ & \multirow{7}{*}{$\begin{array}{c}\mathrm{Chi}^{2}=51.32 \\
p=0.047\end{array}$} \\
\hline $6-10$ & $12(11.3)$ & $12(11.3)$ & \\
\hline $11-15$ & $16(15.1)$ & $16(15.1)$ & \\
\hline $16-20$ & $23(21.7)$ & $31(29.2)$ & \\
\hline $21-25$ & $24(22.6)$ & 19(17.9) & \\
\hline $26-30$ & $15(14.2)$ & $12(11.3)$ & \\
\hline$>30$ & $4(3.8)$ & $2(1.9)$ & \\
\hline \multicolumn{4}{|c|}{ NO. OF EMPLOYMENT ESTABLISHMENTS } \\
\hline 1 & $68(64.2)$ & $78(73,6)$ & \multirow{3}{*}{$\begin{array}{c}\mathrm{Chi}^{2}=0.60 \\
p=0.964\end{array}$} \\
\hline 2 & $31(29.2)$ & $26(24,5)$ & \\
\hline 3 & $7(6.6)$ & $2(1.9)$ & \\
\hline \multicolumn{4}{|l|}{ FORM OF EMPLOYMENT } \\
\hline EMPLOYMENT CONTRACT & $101(95.3)$ & $98(92.5)$ & \multirow{3}{*}{$\begin{array}{c}\mathrm{Chi}^{2}=0.43 \\
p=0.807\end{array}$} \\
\hline COMMISSION CONTRACT & $5(4.7)$ & $3(2.8)$ & \\
\hline CONTRACT & $0(0)$ & $5(4.7)$ & \\
\hline \multicolumn{4}{|l|}{ WORKING TIME } \\
\hline FULL-TIME & $66(61.3)$ & $94(88.7)$ & \multirow{4}{*}{$\begin{array}{c}\mathrm{Chi}^{2}=5.23 \\
\mathrm{p}=0.156\end{array}$} \\
\hline PART-TIME & $2(1.9)$ & $1(0.9)$ & \\
\hline HOUR LIMIT & $2(1.9)$ & $5(4.7)$ & \\
\hline TWO FULL-TIME JOBS & $36(34.0)$ & $6(5.7)$ & \\
\hline
\end{tabular}

${ }^{*}$ chi-square $\left(x^{2}\right)$ test, significance level $p<0.05$ 
Sources of workplace stress among nursing staff in Poland and Lithuania. According to the mean point values of the participants' particular responses, of the many stress factors in the workplace, the strongest stressors to Polish nursing staff were: death and dying (M 19.11; SD \pm 3.95$)$, workload (M 17.21; SD \pm 3.52 ), nurse-physician conflicts (M 11.75; SD \pm 2.95$)$ and uncertainty about diagnostic treatment ( $\mathrm{M}$ 11.75; $\mathrm{SD} \pm 3.15$ ) (Tab. 2). Analysis using the Spearman test demonstrated a correlation between the level of stress experienced and length of service at the limit of statistical significance. The study showed that the level of stress decreased with length of service $(\mathrm{rHO}=-0.18 ; \mathrm{p}=0.0066)$. Analyses using the Mann-Whitney $U$ test confirmed a correlation between the respondents' place of residence and the level of stress. The study showed that those living in urban areas experienced higher levels of stress than those living in rural areas $(Z=-2.12 ; \mathrm{p}=0.034)$. Further analyses revealed no significant correlation between the level of stress and age, or the level of education of the respondents. An analysis of the mean point values of particular responses also led to the determination of the most stressful factors in the daily work of the nursing staff in Lithuania. Of the many stress factors the strongest stressors for the nursing staff employed in Lithuania were: death and dying (M 15.19; SD \pm 3.10 ), workload (M 14.73; SD \pm 3.13 ), nurse-physician conflicts (M 10.42; SD \pm 1.85 ), uncertainty about diagnostic treatment (M 9.22; $\mathrm{SD} \pm 2.0$ ), nurse-nurse conflicts (M 8.75; $\mathrm{SD} \pm 2.12$ ), lack of support ( $\mathrm{M} 7.08 ; \mathrm{SD} \pm 1.62)$ and inadequate preparation (M 6.09; $\mathrm{SD} \pm 1.41$ ) (Tab. 3). An analysis using the Spearman test demonstrated a statistically significant correlation between the level of stress experienced and age $(\mathrm{p}=0.022)$ and length of service $(\mathrm{p}=0.042)$. The study demonstrated that the level of stress decreased with age $(r H O=-0.22 ; p<0.05)$ and length of service $(r H O=-0.20 ; p<0.05)$. The analyses $\mathrm{did}$ not reveal any statistically significant correlation between the level of stress and the educational status of the respondents.

\section{Table 2.}

\begin{tabular}{lccccc}
\hline & \multicolumn{5}{c}{ COUNTRY } \\
\cline { 2 - 6 } STRESSORS & $\begin{array}{c}\text { Lithuania } \\
\text { N=106 }\end{array}$ & $\begin{array}{c}\text { Poland } \\
\text { N=106 }\end{array}$ \\
\cline { 2 - 6 } & M & SD & M & SD & p-value \\
\hline DEATH AND DYING & $\mathbf{1 5 . 1 9}$ & 3.10 & $\mathbf{1 9 . 1 1}$ & 3.95 & $\begin{array}{l}Z=-6.26 \\
p=0.000\end{array}$ \\
\hline NURSE-PHYSICIAN CONFLICTS & $\mathbf{1 0 . 4 2}$ & 1.85 & $\mathbf{1 1 . 8 5}$ & 2.94 & $\begin{array}{l}Z=-3.94 \\
p=0.000\end{array}$ \\
\hline INADEQUATE PREPARATION & $\mathbf{6 . 0 9}$ & 1.41 & $\mathbf{7 . 0 1}$ & 1.69 & $\begin{array}{l}Z=-4.24 \\
p=0.000\end{array}$ \\
\hline LACK OF SUPPORT & $\mathbf{7 . 0 8}$ & 1.62 & $\mathbf{6 . 7 1}$ & 2.13 & $\begin{array}{l}Z=-1.49 \\
p=0.137\end{array}$ \\
\hline NURSE-NURSE CONFLICTS & $\mathbf{8 . 7 5}$ & 2.12 & $\mathbf{1 1 . 8 2}$ & 3.48 & $\begin{array}{l}Z=-6.44 \\
p=0.000\end{array}$ \\
\hline WORKLOAD & $\mathbf{1 4 . 7 3}$ & 3.13 & $\mathbf{1 7 . 2 1}$ & 3.52 & $\begin{array}{l}Z=-4.58 \\
p=0.000\end{array}$ \\
\hline $\begin{array}{l}\text { UNCERTAINTY ABOUT DIAGNOSTIC } \\
\text { TREATMENT }\end{array}$ & $\mathbf{9 . 2 2}$ & 2.00 & $\mathbf{1 1 . 7 5}$ & 3.15 & $\begin{array}{l}Z=-5.97 \\
p=0.000\end{array}$ \\
\hline
\end{tabular}

M - mean; SD - standard deviation; $\mathrm{p}^{*}$ - test of difference between countries, Wilcoxon signed-rank test

Job satisfaction among the nursing staff. Based on an analysis of the collected material, job satisfaction was assessed in positive and negative categories. Taking into account the average scoring (above 4 points) and positive factors influencing the perception of job satisfaction, top scores were given to the following responses: 'I like the things I do at work' (M 5.17; SD \pm 1.42 ), 'I like spending time with my colleagues' (M 5.16; SD \pm 1.08 ), and 'I like the people I work with' (M 4.82; $\mathrm{SD} \pm 1.29$ ). Respondents were proud of their work (M 4.41; $\mathrm{SD} \pm 1.48)$ and assessed the competence of their supervisor equally well (M 4.38; SD \pm 1.57$)$. A high level of job dissatisfaction was related to work organisation: 'I often have the feeling that I do not know what is going on in the company' (M 2.84; $\mathrm{SD} \pm 1.46$ ), 'Many of our rules and procedures make good work performance difficult' (M 2.63; SD \pm 1.55 ), 'I am not satisfied with the benefits I receive' (M 2.51; $\mathrm{SD} \pm 1.98$ ), 'My work is not appreciated" (M 2.30; SD \pm 1.57 ), 'I have a lot of tasks to do at work' (M 2.24; $\mathrm{SD} \pm 1.43$ ), and 'I have a lot of paper work' (M 1.69; SD \pm 1.14 ). The greatest dissatisfaction was recorded for salaries: 'Salary raises are too rare' (M 1.98; SD 1.92), 'In my opinion, my efforts are not remunerated as they should be' (M 1.65; SD \pm 1.19 ), 'When I think about my salary, I feel unappreciated' (M 1.62; $\mathrm{SD} \pm 1.42)$, 'There are few rewards for people working here’ (M 1.60; $\mathrm{SD} \pm 1.40$ ), and 'There are additional benefits I do not receive, although I believe I should' (M 1.56; SD \pm 1.31 ). Calculations based on Pearson's test confirmed that there is a relationship between stress and job satisfaction among the nursing staff $(r=-0.33$; $\mathrm{p}=0.001)$. The greater the stress, the lower the job satisfaction. Further analysis of the collected material based on Spearman's test did not prove any relationship between job satisfaction and education $(\mathrm{rHO}=-0.09 ; \mathrm{p}=0.337)$, work experience of the respondents $(\mathrm{rHO}=0,16 ; \mathrm{p}=0,108)$, and age of the nurses taking part in the study $(\mathrm{rHO}=0.15 ; \mathrm{p}=0.119)$. The study enabled the calculation of a general level of job satisfaction of nurses in Poland. The average of 106,31 (SD \pm 17.43 ) is high and in accordance with the response key, proving that job satisfaction among the nursing staff in Poland is low.

The nursing staff in Lithuania assigned a high level of job satisfaction to: salaries (M 5.23; SD \pm 1.07 ), contacts with colleagues (M 4.78; $\mathrm{SD} \pm 1.13)$, and a positive relationship with supervisors (M 4.02; $\mathrm{SD} \pm 1.37$ ). Such statements as 'I like the things I deal with' (M 4.72; $\mathrm{SD} \pm 1.22$ ), 'I am proud of my work' (M 4.53; SD \pm 1.33 ), 'I like the people I work with' (M 4.55; SD 1.27), and 'My work is pleasant' ( $\mathrm{M} 4.87$; $\mathrm{SD} \pm 1.14$ ) were also assessed positively. Low job satisfaction was recorded for: lack of interest from management staff (M 2.90; $\mathrm{SD} \pm 1.52)$, a lot of office work (M 2.53; SD \pm 1.33 ), many tasks to perform every day (M 2.52, $\mathrm{SD} \pm 1.40$ ), and lack of opportunities for promotion at work (M 2.45; $\mathrm{SD} \pm 1.40)$. The respondents were satisfied with their salary, but gave a negative opinion about the number of raises (M 2.18; SD \pm 1.44 ). The respondents were highly dissatisfied, as expressed in such statements as: 'There are few rewards for people working here' (M 2.50; SD \pm 1.58 ), 'When I think about my salary, I feel unappreciated' (M 2.49; $\mathrm{SD} \pm 1.35)$, and 'There are additional benefits I do not receive, although I think I should' (M 2.41; SD \pm 1.43 ). The average value of credits given under negative categories of work evaluation, given the reversed scoring key, proved that the respondents were highly dissatisfied with their work. A detailed list of the negative and positive indicators of job satisfaction among the nursing staff in Poland and Lithuania is presented in Table 3.

Analysis based on Pearson's correlation test confirmed that there is a relation between stress and job satisfaction 
Table 3.

\begin{tabular}{|c|c|c|c|c|c|}
\hline \multirow[b]{3}{*}{ POSITIVE PERCEPTION OF JOB SATISFACTION } & \multicolumn{4}{|c|}{ COUNTRY } & \multirow{3}{*}{ p-value } \\
\hline & \multicolumn{2}{|c|}{ Lithuania; $\mathrm{N}=106$} & \multicolumn{2}{|c|}{ Poland; $\mathrm{N}=106$} & \\
\hline & M & SD & M & SD & \\
\hline I THINK THAT I RECEIVE GOOD PAY FOR MY WORK & 5.23 & 1.07 & 1.63 & 1.42 & $Z=-8.57 ; p=0.000$ \\
\hline MY SUPERVISOR IS FULLY COMPETENT IN HIS/HER WORK & 4.23 & 1.33 & 4.38 & 1.57 & $Z=-0.63 ; p=0.527$ \\
\hline WHEN I DO MY JOB WELL, I AM ADEQUATELY APPRECIATED & 3.63 & 1.40 & 2.49 & 1.58 & $Z=-5.12 ; p=0.000$ \\
\hline COMMUNICATION AT MY COMPANY SEEMS TO BE GOOD & 4.01 & 1.25 & 3.27 & 1.55 & $Z=-3.73 ; p=0.000$ \\
\hline ANYONE WHO DOES HIS/HER JOB WELL HAS GOOD CHANCES FOR PROMOTION & 2.80 & 1.69 & 2.10 & 1.49 & $Z=-3.18 ; p=0.001$ \\
\hline THE BENEFITS I RECEIVE ARE COMPARABLE TO THOSE OFFERED BY MOST COMPANIES & 3.03 & 1.61 & 2.08 & 1.65 & $Z=-3.82 ; p=0.000$ \\
\hline BUREAUCRACY RARELY DISTURBS MY WORK & 3.47 & 1.37 & 2.95 & 1.76 & $Z=-2.30 ; p=0.022$ \\
\hline I LIKE THE THINGS I DO AT WORK & 4.72 & 1.22 & 5.17 & 1.42 & $Z=-2.69 ; p=0.007$ \\
\hline THE PACKAGE OF BENEFITS WE RECEIVE IS FAIR & 3.55 & 1.47 & 1.76 & 1.44 & $Z=-6.61 ; p=0.000$ \\
\hline I LIKE SPENDING TIME WITH MY COLLEAGUES & 4.78 & 1.13 & 5.16 & 1.08 & $Z=-2.54 ; p=0.011$ \\
\hline I AM PROUD OF MY WORK & 4.53 & 1.33 & 4.41 & 1.48 & $Z=-0.74 ; p=0.461$ \\
\hline I AM SATISFIED WITH THE PROSPECT OF A SALARY RAISE IN THE FUTURE & 3.24 & 1.94 & 1.91 & 1.60 & $Z=-4.83 ; p=0.000$ \\
\hline I LIKE MY SUPERVISOR & 4.02 & 1.37 & 4.57 & 1.54 & $Z=-2.49 ; p=0.013$ \\
\hline I AM SATISFIED WITH THE PROMOTION OPPORTUNITIES & 3.19 & 1.59 & 2.13 & 1.45 & $Z=-4.30 ; p=0.000$ \\
\hline MY WORK IS PLEASANT & 4.87 & 1.14 & 3.96 & 1.52 & $Z=-4.58 ; p=0.000$ \\
\hline \multicolumn{6}{|l|}{ NEGATIVE PERCEPTION OF JOB SATISFACTION } \\
\hline OPPORTUNITIES FOR PROMOTION ARE LIMITED AT MY WORKTHE & 2.45 & 1.40 & 3.08 & 1.83 & $Z=-2.67 ; p=0.008$ \\
\hline I AM NOT SATISFIED WITH THE BENEFITS I RECEIVE & 3.42 & 1.43 & 2.51 & 1.98 & $Z=-3.28 ; p=0.001$ \\
\hline MANY OF OUR RULES AND PROCEDURES MAKE IT DIFFICULT TO DO OUR JOB WELL & 2.83 & 1.33 & 2.63 & 1.55 & $Z=-1.27 ; p=0.206$ \\
\hline I SOMETIMES THINK THAT MY WORK HAS NO SENSE & 4.15 & 1.54 & 3.11 & 1.81 & $Z=-4.02 ; p=0.000$ \\
\hline MY SUPERVISOR IS UNFAIR TO ME & 4.18 & 1.53 & 4.36 & 1.72 & $Z=-0.75 ; p=0.453$ \\
\hline I THINK THAT MY WORK IS UNAPPRECIATED & 3.27 & 1.56 & 2.30 & 1.57 & $Z=-3.99 ; p=0.000$ \\
\hline I BELIEVE THAT I MUST WORK HARDER BECAUSE OF THE INCOMPETENCE OF MY COLLEAGUES & 4.09 & 1.45 & 3.51 & 1.71 & $Z=-3.09 ; p=0.002$ \\
\hline THE GOALS OF THE COMPANY I WORK WITH ARE NOT CLEAR & 4.24 & 1.38 & 3.61 & 1.72 & $Z=-2.81 ; p=0.005$ \\
\hline WHEN I THINK ABOUT MY SALARY, I FEEL UNAPPRECIATED & 2.49 & 1.35 & 1.62 & 1.42 & $Z=-4.38 ; p=0.000$ \\
\hline MY SUPERVISOR IS NOT SUFFICIENTLY INTERESTED IN THE FEELINGS OF HIS/HER SUBORDINATES & 2.90 & 1.52 & 3.40 & 1.80 & $Z=-2.08 ; p=0.037$ \\
\hline THERE ARE FEW REWARDS FOR THOSE WHO WORK HERE & 2.50 & 1.58 & 1.60 & 1.45 & $Z=-4.19 ; p=0.000$ \\
\hline I HAVE A LOT OF DUTIES TO DO AT WORK & 2.52 & 1.40 & 2.24 & 1.43 & $Z=-1.80 ; p=0.072$ \\
\hline I OFTEN HAVE THE FEELING THAT I DO NOT KNOW WHAT IS GOING ON IN MY COMPANY & 3.24 & 1.53 & 2.84 & 1.46 & $Z=-2.14 ; p=0.033$ \\
\hline THERE ARE ADDITIONAL BENEFITS WHICH I DO NOT RECEIVE, ALTHOUGH I SHOULD & 2.41 & 1.43 & 1.56 & 1.31 & $Z=-4.23 ; p=0.000$ \\
\hline I HAVE A LOT OF PAPER WORK & 2.53 & 1.33 & 1.69 & 1.14 & $Z=-4.38 ; p=0.000$ \\
\hline I THINK THAT MY EFFORTS ARE NOT SUFFICIENTLY REWARDED & 2.50 & 1.21 & 1.65 & 1.19 & $Z=-4.69 ; p=0.000$ \\
\hline THERE ARE MANY ARGUMENTS AND INTERNAL CONFLICTS AT WORK & 3.67 & 1.60 & 3.41 & 1.64 & $Z=-1.10 ; p=0.272$ \\
\hline OUR DUTIES ARE NOT FULLY EXPLAINED & 2.63 & 1.41 & 2.35 & 1.36 & $Z=-5.19 ; p=0.000$ \\
\hline
\end{tabular}

$\mathrm{M}$ - mean; SD - standard deviation; $\mathrm{P}^{*}$ - test of difference between countries. Wilcoxon signed-rank test

$(\mathrm{r}=0.34 ; \mathrm{p}=0.001)$. The study confirmed that the greater the stress, the lower the job satisfaction. Analysis based on Spearman's correlation test confirmed that there is a material relationship between job satisfaction and the work experience and age of the respondents $(\mathrm{rHO}=0.22 ; \mathrm{p}=0.021)$. No statistically significant relationship was noted between job satisfaction and work experience $(\mathrm{rHO}=0.09 ; \mathrm{p}=0.374)$ or the education of the respondents $(\mathrm{rHO}=-0.01 ; \mathrm{p}=0.940)$. To verify further hypotheses, a non-parametric test of statistical significance was used - the Mann Whitney (U-test). The study did not show a relationship between job satisfaction and the workplace $(Z=-0.09 ; p=0.922)$ or the working time system of the respondents $(\mathrm{Z}=-1.05 ; \mathrm{p}=0.293)$.

Based on the analysis of the collected material, job satisfaction of the nursing staff in Lithuania was subject to an overall assessment. The obtained average was 125,42 $(\mathrm{SD} \pm 18.15)$. This is high and proved that the respondents had an ambivalent attitude towards their job satisfaction. The general level of job satisfaction calculated on the basis of Wilcoxon's test confirmed that there are significant differences in job satisfaction in Poland and Lithuania $(\mathrm{Z}=-6.27 ; \mathrm{p}<0.001)$. 


\section{DISCUSSION}

In the opinion of many researchers, stress is an inherent part of the work of the nursing staff, which influences their capacity of adapting to professional requirements [2, 25]. Long-lasting high stress is directly connected with: worsening physical and mental health of the nursing staff, absence at work, eagerness to change one's job, burnout, and resignation from one's professional career [26]. Exposure to stress factors may contribute to loss of weight, as well as a willingness to use various types of stimulants like alcohol or drugs [27].

Apart from stress factors, the lack of job satisfaction among the nursing staff can be a significant problem which influences service quality and patient satisfaction. The issue of working conditions of the nursing staff has already been mentioned for a long time in the specialised literature. Many researchers indicate that the working conditions and number of nurses or their exposure to stress factors have a significant impact on the safety of a patient $[28,29]$. Not all changes in the environment and working conditions of nurses must be connected with financial expenditure. Some stress factors, like conflicts between nurses or between nurses and doctors, or the lack of support and interest from management staff, can be modified. They mostly depend on internal actions taken by health care centres to improve their work organisation.

A study carried out by McHugh on a sample of 95,000 nurses [30] showed that the problem of high burnout and low job satisfaction was recorded in the case of the majority of personnel working at hospitals and nursing homes. Employees negatively assessed mainly such factors as the lack of opportunities for promotion and professional development, financial issues and welfare allowances [30]. The problem of low job satisfaction does not apply to nurses working in other places, like the pharmaceutical industry. Thus, it is not surprising that more and more nurses do not work in their profession or decide to change their employment profile.

The current study enabled identification of the greatest stress factors in the work of the nursing staff in Poland and Lithuania. A detailed analysis of the material confirmed that the category of death and dying generated a high level of stress. The work of nursing staff largely depends on cooperation and interaction among the therapeutic team, the patients and their families. This entails a very strong emotional involvement [31]. The nurse's emotional competence requires her to be able to manage and cope with her own emotions, as well as the emotions of her patients [32]. Detailed analyses of the collected material have confirmed a high rate of elevated stress in the category of death and dying among the nursing staff in Poland and Lithuania. According to Steinhauser et al., this can be due to inadequate preparation of the medical staff for the heavy mental strain associated with death [33]. While caring for a dying patient, nurses notice the meaning and significance of their presence - yet they do not always feel well-prepared for this. The studies conducted by Ryan and Jezewska [34] confirm that over $60 \%$ of nurses feel uncertain while providing care to terminal patients. In the authors' own research, the nursing staff also pointed to the lack of adequate preparation for terminal care, insufficient knowledge, a sense of helplessness, and lack of sufficient time [35].

Further stressors in the daily work of nursing staff are nurse-physician conflicts and significant workload. The question of lack of appropriate communication between nurses and physicians is present in numerous scientific studies $[36,37]$ and may be connected with the enlargement of the scope of professional duties imposed on nurses. In the presented study, the nursing staff of Poland and Lithuania clearly identified nurse-physician conflicts as the principal source of stress in their professional work. The high score for this indicator may be linked to the respondents' level of education. It should be noted that both in Poland and Lithuania, compared to other European countries, for a long time the nursing profession was deprived of professional independence, and a nurse was perceived as a physician's helper $[38,39]$. Changes in the system of healthcare education, with a view to standardizing the professional competences of nursing staff in the countries of the European Union, have led to increased professional independence and improved clinical skills. An analysis of previous literature clearly demonstrates that a good theoretical background and diploma or other postgraduate studies in nursing, translate into a higher awareness and improved skills of nursing staff [40]. Education is also strongly correlated with nursing staff actively employing scientific research in their daily clinical practice [41].

Another equally important source of nursing stress is excessive workload. Considering the growing shortages in nursing staff [20] and the enlargement of their scope of work duties, the problem of increased workload is becoming more and more distinct and severe $[42,43]$. A review of the scientific research to-date reveals that excessive workload affects various nursing specialties $[42,43]$ and is one of the key factors determining the quality of care [11], the incidence of adverse events [44] and the phenomenon of professional burnout [45].

The presented study shows a significant relationship between the level of stress, length of service, and age of the respondents, both with respect to Polish and Lithuanian nurses. These results are similar to the studies by other researchers. Winwood et al. [46] proved that nursing staff with a longer time of service felt much less tired and stressed at work. The authors confirmed that nursing staff with a longer time of service adapt to the varying conditions of work much faster, and cope with stress with much greater ease [46]. The study did not show any statistically significant correlations between the level of stress, work/life balance, or working time. The results obtained, however, differ from those obtained by other authors. Analyses conducted by Shen et al. demonstrated that nurses who were widows or divorcees experienced much higher stress levels than married nurses [47]. Other studies indicate a link between the level of professional stress and having children [48].

Nursing staff in their daily care for patients frequently observe that despite heroic efforts at treatment, the patient's condition deteriorates day by day. The problem of the socalled persistent/obstinate therapies is broadly discussed in the literature. Nurses have often pointed to undertaking aggressive therapies in terminal patients [49]. Decisions regarding the patient's treatment and therapies are the responsibility of the physicians [37]. Nursing staff hardly ever formally participate in the decision-making process regarding the therapeutic methods used, even though patient care and nursing are among the key tasks of nursing staff [50]. The current study confirms that misunderstandings and doubts concerning therapeutic measures taken are still significant stressors for nurses. 
The second main factor studied was the relationship between stress and job satisfaction. A careful analysis of the data collected confirmed a relationship between stress and job satisfaction. The outcome of the current study is similar to the outcome of the study carried out by Le Blanc et al. [51] who confirmed that the increase in job satisfaction is strongly connected with the increase in professional requirements. The researchers proved that the most difficult duties requiring substantial involvement from the nursing staff (e.g. participation in medical treatment and patient care) are connected with high job satisfaction. Organisational duties (contacts between nurses and their supervisors, doctors and colleagues) were found to be less demanding and brought about the lowest job satisfaction.

Another aspect of the current study was separating the positive and negative factors based on which work is perceived as satisfactory or not. Analysis of the material collected proved that nurses both in Poland and Lithuania are proud of their profession, like their job and enjoy contacts with colleagues. The differences in their attitude to their salaries are interesting. Both groups agreed that their salaries are disproportionate to their involvement and professional duties. All nurses felt that they are unappreciated and that their professional skills are undervalued. In the opinion of the nursing staff in Lithuania, there is a need for better salaries; nevertheless, most respondents highly evaluated their job satisfaction in terms of salary. Polish nurses were not satisfied with their salaries and did not notice any desired changes in this area.

As regards factors contributing to the negative perception of organisation and to high job dissatisfaction at the same time, the respondents referred to organisational errors at their workplace and a substantial work load. The respondents stated that they did not know the company's goals thoroughly and that opportunities for professional promotion were still a great problem. Nurses also felt a significant work load when their colleagues did not fulfil all their duties. The outcome of the presented study is similar to the outcome of studies carried out by other authors $[52,53,54]$. The study of many health care centres carried out by Aiken et al. confirmed that over a half of nurses who participated in the study referred to significant organisational errors at their workplaces. The respondents noticed a significant load of duties that were very often not connected with patient care, as well as a lack of opportunities for professional promotion, and conflicts with their supervisors [55].

The presented study enabled assessment of the overall level of job satisfaction in the analysed group of nurses. The nursing staff in Poland were highly dissatisfied, whereas Lithuanian nurses had mixed feelings about their job satisfaction. Because of the lack of detailed information about job satisfaction among nurses in Lithuania, it is difficult to compare the results with the results available in the literature, and with the results of Polish studies. The fact that the results of the current study cannot be directly compared with the results available in the literature may be connected with the use of various types of scales in the assessment of job satisfaction, as they not always refer to the assessment of overall job satisfaction based on the JSS scale [54, 56,57]. Analysis of the material confirmed that there is a relationship between age and job satisfaction of the nursing staff. The results of the analysis is similar to the results of studies carried out by other authors. The study carried out by Scot et al. confirms that younger nurses are most exposed to stress factors in their work, which has a great impact on the development of their long-term job satisfaction. Some authors also point out that there is a relationship between job satisfaction and the level of education of the nurses taking part in the study. The study suggests that higher education translates into higher job satisfaction $[55,58]$. This relationship is confirmed by the analysis of the Polish material. The study carried out by Zawacki et al. also confirmed that there is a relationship between gender and job satisfaction [59]. Zawacki et al. reported that male nurses tend to be somewhat more satisfied with their supervisors than female nurses. In the current study, the fact that women outnumbered men made it impossible to analyse the differences connected with gender.

Limitations of the study. The research did not analyse all stress factors existing in the work of nursing staff. The analysis did not take into account the respondents' personalities or prior experience in stressful situations. The consequences of exposure to long-lasting stress in the work of the nursing staff was also not taken into account. The specialised literature shows that this is very important for the development of serious health disorders, like sleep disorder, depression or mood disorders. Analysis of job satisfaction did not take into account such factors as expectations related to work, the experience of employees or social and economic conditions. The literature shows that these factors have a significant impact on the manner of the evaluation and perception of job satisfaction.

The study was also limited by the sample chosen for the purpose of the study. The method applied did not take into account a control group.

\section{CONCLUSIONS}

The number of nursing staff in the countries of Europe, including Poland and Lithuania, has been decreasing year by year. This is connected with an increasing demand for nursing care as a result of the ageing of society. Another most frequent factor is resignation from one's job or migration of the nursing staff to highly-developed countries which provide much better working and payment conditions. Analysis of the results of the study confirms that the level of stress at work and the related job satisfaction are of great importance for the recruitment of new employees. The analyses show that the dying and death of patients presents a substantial workload, and that conflicts between nurses and doctors are still great problems for the nursing staff. The study also confirmed a relationship between exposure to stress and job satisfaction. Taking the above into account, it must be remembered that both stress and job satisfaction should be analysed jointly as a multidimensional phenomenon. The analyses confirm that high job dissatisfaction among the nursing staff is connected with bad internal organisation of the workplace, conflicts with supervisors, and a lack of understanding between nurses and their supervisors.

Another problem that still exists is the lack of opportunities for professional promotion. This is confirmed not only by studies carried out in Lithuania and Poland, but by findings recorded in highly developed countries like the USA and the UK. It is heartening that the nursing staff are highly satisfied with or even proud of their job. The outcome of 
the current allowed the drawing of the conclusion that the nursing profession is not chosen accidentally, but it is chosen by people that have a vocation to be a nurse.

The results of this study can be useful in particular for management staff, managers, and chief and coordinating nurses in the process of identifying stress factors in the everyday work of the nursing staff, and establishing such working conditions that favour professional development and reduce the risk of employee migration to other workplaces. An undeniable problem connected with the development of nursing, not only in such countries as Poland and Lithuania, is the lack of a clearly defined professional career path. The improvement of professional qualifications is not always connected with adequate payment, and the nursing staff feel unappreciated or even marginalised in comparison to other professions.

\section{REFERENCES}

1. Yates P, Benson E, Harris A. An investigation of factors supporting the psychological health of staff in a UK emergency department. Emerg Med J. 2012; 29 (7): 533-535

2. Ulrich C.M, et al. Everyday ethics: ethical issues and stress in nursing practice. J Adv Nurs. 2010; 66 (11): 2510-2519.

3. Folkman S. Stress, Appraisal and Coping. In: Gellman M.,Turner JR (ed). Encyclopedia of Behavioral Medicine. Springer. New York, 2013. pp 1913-1915.

4. Olofsson B, Bengtsson C, Brink E. Absence of response: a study of nurses' experience of stress in the workplace. J Nurs Manag. 2003; 11(5): 351-358.

5. Zhou H, Gong Y. Relationship between occupational stress and coping strategy among operating theatre nurses in China: a questionnaire survey. J Nurs Manag. 2015; 23(1): 96-106.

6. Simones S, Villeneuve M, Hurst J. OECD Health Working Papers No. 19 Tackling Nurse Shortage in OECD Countries. DELSA/ELSA/WD/ HEA(2005)1. http://www.oecd.org/health/health-systems/34571365. pdf. (accessed: 11.01.2014).

7. Bartman T, Joiner T, Stanton P. Factors affecting the job stress and job satisfaction of Australian nurses: Implications for recruitment and retention. Contemp Nurse 2004; 17(3): 293-304.

8. Larrabee J, et al. Predicting registered nurse job satisfaction and intent to leave. J Nur Adm 2003; 33(5): 271-283.

9. Spector PE, Job Satisfaction: Application, Assessment, Causes, and Consequences. SAGE Publications, London, 1997. p.1-68.

10. Lu H, While K, Bariball K. Job satisfaction among nurses: a literature review. Int Nurs Stu. 2005; 42(2): 211-27.

11. Aiken LH, Clarke SP, Sloane DM, Sochalski J, Silber JH. Hospital nurse staffing and patient mortality, nurse burnout, and job dissatisfaction. JAMA 2002; 288: 1987-1993.

12. Kapborg I. The nursing education programme in Lithuania: voices of student nurses. J Adv Nurs. 2000; 32(4): 857-863.

13. Sztembis B. The past, present and the future of nursing education in Poland: stages, condition and activities. Int Nurs Rev. 2006; 53: 102-109.

14. Galdikien N, Asikainen P, Balčiūnas S, Suominen T. Do nurses feel stressed? A perspective from primary health care. Nurs Health Sci. 2014; 16(3): 327-34.

15. Vimantaite R, Seskevicius A. The burnout syndrome among nurses working in Lithuanian cardiac surgery centers. Medicina (Kaunas) 2006; 42(7): 600-5.

16. Sakowski P. Job satisfaction of occupational medicine nurses in Poland. Int J Occup Med Environ Health. 2012; 25 (1): 51-58.

17. Public Research Opinion Center. Research Reports. Jobs at Prestige Professions http://www.cbos.pl/SPISKOM.POL/2013/K_164_13.PDF (accessed: 02.14.17).

18. Zielińska-Więczkowska H, Buśka A. Professional Satisfaction of Nurses in Light of Selected Factors of Work Environment. Nursing in the 21st Century 2010; 3-4: 32-33.

19. Franek G., Kulik H, Ferdyn M. Interest in Nursing Profession among high school youth. Nursing Topics 2012; 20: 423-430.

20. Eurostat. Healthcare personnel statistics - nursing and caring professionals. 2017. http://ec.europa.eu/eurostat/statistics-explained/
index.php/Healthcare_personnel_statistics__nursing_and_caring professionals. (accessed: 11.02.17).

21. Global Health Facts. http://kff.org/global-indicator/nurses-andmidwives/. (accessed: 04.04.15)

22. Gray-Toft P, Anderson JA. The Nursing Stress Scale: development of an instrument. J Behav Assess. 1981; 3: 11-23.

23. Spector E. Interpreting Satisfaction Scores with the Job Satisfaction Survey. http://shell.cas.usf.edu/ pspector/scales/jssinterpretation.html (accessed:10.04.2016).

24. Spector E. Interpreting Satisfaction Scores with the Job Satisfaction Survey. http://shell.cas.usf.edu/ pspector/scales/jssinterpretation.html. (accessed: 10.04.2016).

25. Xianyu Y, Lambert V. A. Investigation of the relationships among workplace stressors, ways of coping, and the mental health of Chinese head nurses. Nurs Health Sci. 2006; 8(3): 147-155.

26. Burke R Workaholism in organizations: psychological and physical well-being consequences. Stress and Health 200; 16(1): 11-6.

27. Riklikienè O, Krušinskaitė D, Gatautis R, Bagdonaitė Ž. Nurses' Work-Related Stress, Job Satisfaction, and Intent to Leave: A Survey in Primary Health Care Centers. NERP 2015; 5(1): 11-20.

28. Vahey DC, Aiken LH, Sloane DM, Clarke SP, Vargas D. Nurse burnout and patient satisfaction. Med Care 2004; 42(2): 57-66.

29. Aiken LH, Clarke SP, Sloane DM, Lake ET, Cheney T. Effects of hospital care environment on patient mortality and nurse outcomes. J Nurs Adm. 38(5): 223-229.

30. McHugh MD, Kutney-Lee A, Cimiotti JP, Sloane DM, Aiken LH. Nurses' widespread job dissatisfaction, burnout, and frustration with health benefits signal problems for patient care. Health Aff (Millwood) 2011; 30(2): 202-10.

31. Skilbeck J, Payne S. Emotional support and the role of the clinical nurse specialist in palliative care. J Adv Nurs. 2003; 43: 521-530.

32. Teng CI, Chang SS, Hsu, KH. Emotional stability of nurses: impact on patient safety. J Adv Nurs. 2009; 65: 2088-96.

33. Steinhauser KE. et al. Preparing for the end of life: preferences of patients, families, physicians, and other care providers. J Pain Symptom Manage 2001; 22: 727-737.

34. Ryan D, Jezewski MA. Knowledge, attitudes, experiences, and confidence of nurses in completing advance directives: a systematic synthesis of three studies. J Nurs Res. 2012; 20(2): 131-141.

35. Widmark-Petersson V, von Essen L, Sjödén PO. Perceptions of caring among patients with cancer and their staff. Differences and disagreements. Cancer Nurs. 2000; 23: 32-39.

36. Piers RD, et al. Perceptions of Appropriateness of Care among European and Israeli Intensive Care Unit Nurses and Physicians. JAMA 2011; 306: 2694-703.

37. Wujtewicz M, Wujtewicz MN, Owczuk R. Conflicts in the intensive care unit. Anaesthesiol Intensive Ther. 2015; 47(4): 360-362.

38. Istomina $\mathrm{N}$, et al. Competence of nurses and factors associated with it. Medicina (Kaunas) 2011; 47: 230-237.

39. Sztembis B. The past, present and the future of nursing education in Poland: stages, condition and activities. Int Nurs Rev. 2006; 53(2): 102-109.

40. Moore P. Decision-making in professional practice. Br J Nurs. 1996; 5(10): 635-640.

41. Mehrdad N, Joolaee S. Nursing faculties' knowledge and attitude on evidence-based practice. Iran J Nurs Midwifery Res. 2012; 17: 506-511.

42. Nishizaki Y, et al. Relationship between nursing workloads and patient safety incidents. J Multidiscip Healthc 2010; 3: 49-54.

43. Jackson A, Carberry M. The advance nurse practitioner in critical care: A workload evaluation. Nurs Crit Care 2015; 20: 71-77.

44. Needleman J, Buerhaus P, Mattke S, Stewart M, Zelevinsky K. Nursestaffing levels and the quality of care in hospitals. N Engl J Med. 2002; 346: 1715-1722.

45. Portoghese I, Galletta M, Coppola R, Finco G, Campagna M. Burnout and Workload Among Health Care Workers: The Moderating Role of Job Control. Saf Health Work 2014; 5(3): 152-157.

46. Winwood PC, Winefield A.H, Lushington K. Work-related fatigue and recovery: the contribution of age, domestic responsibilities and shiftwork. J Adv Nurs. 2006; 56(4):438-449.

47. Shen $\mathrm{H}$, et al. Occupational stress in nurses in psychiatric institutions in Taiwan. J Occup Health 2005; 47(3): 218-255.

48. Zhou H, Gong YH. Relationship between occupational stress and coping strategy among operating theatre nurses in China: a questionnaire survey. J Nurs Manag. 2015; 23(1): 96-106.

49. Seymour JE. Negotiating natural death in intensive care. Soc Sci Med. 2000; 51(8): 1241-1252. 
50. Ferrand E, et al. Discrepancies between perceptions by physicians and nursing staff of intensive care unit end-of-life decisions. Am J Respir Crit Care Med. 2003; 167: 1310-5.

51. Le Blanc P.M., de Jonge J., de Rijk A.E. \& Schaufeli W.B. Well-being of intensive care nurses (WEBIC): a job analytic approach. J Adv Nurs. 2001; 36: 460-470.

52. Kutney-Lee A, Wu ES, Sloane DM \& Aiken LH. Changes in hospital nurse work environments and nurse job outcomes: An analysis of panel data. Int J Nurs Stud. 2013; 50(2): 195 - 201. doi: 10.1016/j. ijnurstu.2012.07.014.

53. Lu H, Barriball KL, Zhang X, While AE. Job satisfaction among hospital nurses revisited: a systematic review. Int J Nurs Stud. 2012; 49(8): 1017-38.
54. Wiederszal-Bazyl M. Copenhagen Psychosocial Questionanarie (COPSOQ) - Psychometric propertiesof selected scales in the Polish version. Med Pr. 2017; 16; 68(3): 329-348.

55. Aiken L, et al. Nurses' reports on hospital care in five countries. Health Aff. 2001; 20(3): 43-53

56. Hudgins TA. Resilience, job satisfaction and anticipated turnover in nurse leaders. J Nurs Manag. 2015; 24(1): E62-9.

57. Brayer A, Foley M, Doroszkiewicz H, Jamiołkowski J, Marcinowicz L, Job satisfaction among masters in nursing in Central and East Poland: a preliminary study. Family Medicine \& Primary Care Rev. 2017; 19: 1.

58. Lorber M, Skela Savič B. Job satisfaction of nurses and identifying factors of job satisfaction in Slovenian Hospitals. Croat Med J. 2012; 53(3): 263-70.

59. Zawacki RA, Shahan R. \& Carey M. Who has higher job satisfaction. Male or female nurses? Nurs Manage 1995; 26(1): 54-55. 